\title{
Extrapyramidal dysfunction with cerebral arteriovenous malformations ${ }^{1}$
}

\author{
JOAO LOBO-ANTUNES, MELVIN D. YAHR ${ }^{2}$, AND SADEK K. HILAL \\ From the Clinical Center for Research in Parkinsonism and Allied Diseases, The Mount Sinai \\ School of Medicine, Columbia University College of Physicians and Surgeons, and the Departments of \\ Neurosurgery and Neuroradiology, New York Neurological Institute, New York, N.Y., U.S.A.
}

SYNOPSIS Arteriovenous malformations have only rarely been implicated as a cause of basal ganglia dysfunction. In four instances where such a lesion was uncovered, abnormal involuntary movements were present. In two, tremor involving the contralateral limbs occurred, while in others the head and neck were involved in dystonic movements and posture. The clinical and angiographic characteristics of these four patients have been assessed and are presented in detail in this report. The possible mechanism by which arteriovenous malformations may disturb the internal circuitry of the basal ganglia and induce symptoms are discussed.

The clinical manifestations and natural history of arteriovenous malformations of the brain (AVM) have been previously well documented (Olivecrona and Riives, 1948; Mackenzie, 1953; Paterson and McKissock, 1956; Anderson and Korbin, 1958; Tonnis et al., 1958; Svien and McRae, 1965; Perret and Nishioka, 1966; Kelly et al., 1969; Moody and Poppen, 1970). In their classical form they are distinguished by the occurrence of hemicrania, convulsive seizures, and subarachnoid bleeding. In most instances, and usually over a period of time, a variety of neurological deficits accrue to this triad, though extrapyramidal signs appear to be a rarity. In our review of several reported series of arteriovenous malformations encompassing more than a thousand cases, abnormal involuntary movements were described on only one occasion (Paterson and McKissock, 1956). An additional case was briefly reported by Shaw et al. (1972).

It is the exception rather than the rule to encounter discrete structural lesions of the brain as an underlying cause of classical extrapyramidal disorders. It is, therefore, of more than passing interest to find four cases in which specific involuntary movement disorders were a major

\footnotetext{
1 Supported in part by the Parkinson Disease Foundation, New York and NINDS Grant No. 05184.

2 Address for reprints: Dr. Yahr, Mount Sinai School of Medicine.
}

manifestation of a cerebral arteriovenous malformation. In three of these cases the vessels involved were those that normally supply the basal ganglia structures. The clinical and angiographic features of these exceptional cases, as well as some physiopathological implications are the basis of this report.

\section{CASE 1}

This 21 year old right-handed man was admitted to the Neurological Institute for the first time in 1964. He was the product of a full-term uncomplicated pregnancy and, although he was always considered to be a clumsy child, his milestones were normal. When he was 1 year old the mother noted peculiar waving movements of the right arm. Over the years this progressed and at the age of 13 years he was noted to have tremor of the right hand, and trouble in performing fine movements; his handwriting deteriorated and he began to prefer the left hand. At the age of 14 , he had been admitted to another hospital for evaluation. He was thought to be mentally slow; nystagmus on lateral and upward gaze and bilateral hypertrophy of the sternocleidomastoid muscles were noted. There was an involuntary pronation-supination tremor of the right arm, and the performance of rapid succession movements with the right foot was defective. Radiographs of the skull revealed a $10 \mathrm{~mm}$ left to right shift of the pineal gland. A pneumoencephalogram failed to visualize 


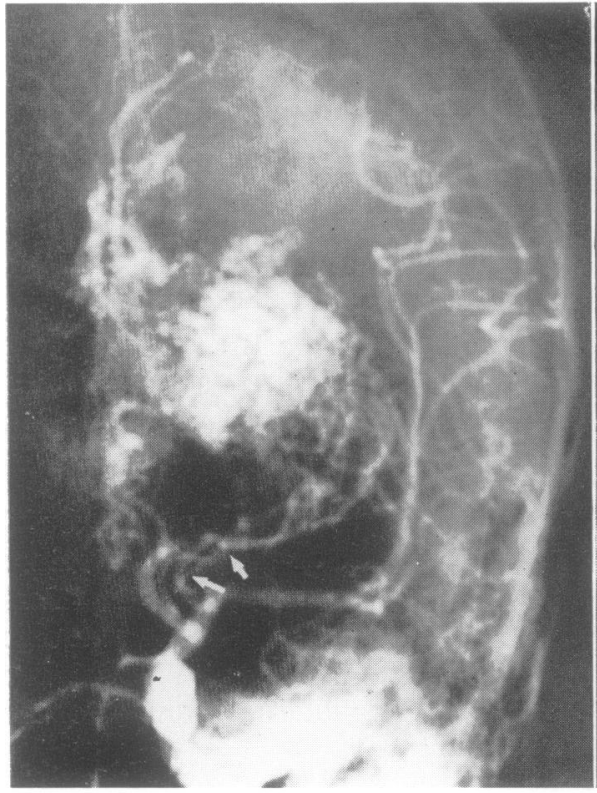

(a)

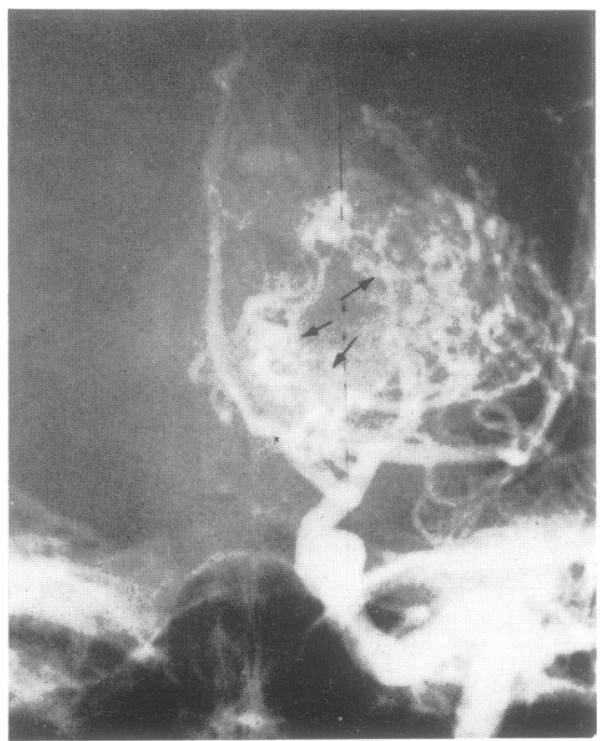

(c)

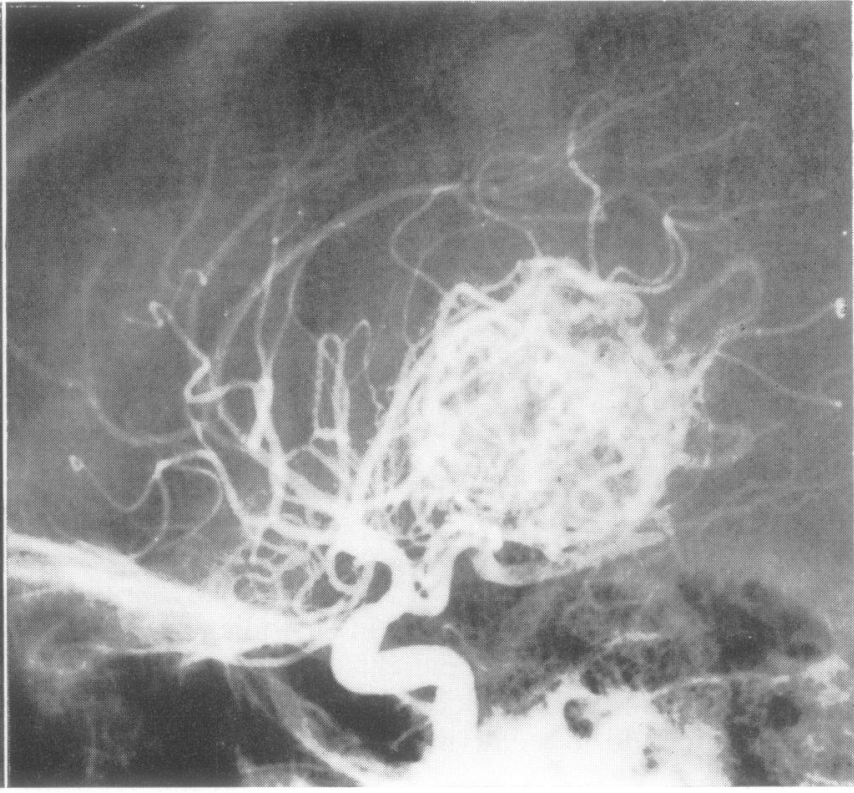

(b)

FIG. 1. Case 1. (a) AP view of the left carotid angiogram (initial study). Deep AVM supplied predominantly by the anterior choroidal artery (arrows), and posterior cerebral artery. A smaller supply may be coming from the lenticulostriate vessels. (b) Lateral view of the same case. (c) AP view of the left carotid angiogram obtained at the time of the second admission. Note the shift of the anterior cerebral artery and lateral displacement of the middle cerebral artery. Also note the increased size of the avascular zone in the medial aspect of the malformation (arrows).

adequately the ventricular system, though the basal cisterns and sulci were normal.

Except for a slight increase in tremor his condition remained essentially unchanged. In 1964, he was admitted to the New York Neurological Institute for evaluation. Apart from a mild right-sided reflex preponderance, and a questionable left central facial paresis his neurological examination was unchanged. An intravenous RISA scan $\left(I_{131}\right)$ revealed an area of increased uptake over the left mid-temporal region thought to be of vascular origin. A pneumoencephalogram revealed a slight displace- 
ment to the right of the posterior portion of the third ventricle. A lumbar puncture disclosed cerebrospinal fluid under normal pressure with a protein content of $59 \mathrm{mg} / 100 \mathrm{ml}$. An electroencephalogram was normal. An angiographic study was refused by the family and the patient was discharged.

He was readmitted in July 1965 . On the day of admission he awoke with a severe, generalized headache, followed by nausea and vomiting. Neurological examination on admission revealed a lethargic patient with marked nuchal rigidity and positive meningeal signs. Speech was dysarthric and mild weakness and increase in tone of the right upper extremity were noted. There were flailing dystonic movements of the right arm and motor coordination was poor. Pain, touch, position, and vibratory sensations as well as stereognostic sensibilities were decreased over the right hand. There was paralysis of upward gaze. A right central facial paresis was present and on protrusion the tongue deviated to the right. No bruits were heard. Again, bilateral hypertrophy of the sternocleidomastoid muscles was observed. Lumbar puncture revealed grossly bloody fluid under increased pressure. An angiographic study revealed a large arteriovenous malformation occupying the left basal ganglia, thalamus, and upper mesencephalon which was fed predominantly by the anterior choroidal artery in its lateral aspect, and by branches of the posterior cerebral artery in its medial aspect (Fig. 1a, b). The major drainage was through the basilar vein which was markedly enlarged in its posterior portion. Approximately a week after the haemorrhage, it was noted that the abnormal movements had disappeared, but the patient maintained a dystonic posture of the right hand. He received a course of radiotherapy and was discharged one month later.

He was readmitted two months later with a second episode of subarachnoid bleeding. His neurological status remained essentially unchanged. Two further haemorrhages occurred during his hospitalization. He did well until May 1972 when he was readmitted after another episode of bleeding. His neurological condition was essentially unchanged. A second angiographic study was performed. A $7 \mathrm{~mm}$ shift of the left anterior cerebral artery to the right, and a lateral displacement of the middle cerebral artery were present indicating a centrosylvian mass effect which was much greater than on the initial studies (Fig. 1c). There was also an increase in the size of the lucent area in the medial aspect of the malformation suggesting the presence of a haematoma.

CASE 2

This 39 year old woman was admitted to the New
York Neurological Institute in February 1959. Five days before admission she experienced sudden, severe, generalized headaches, followed by vomiting. She was admitted to another hospital and a mild left hemiparesis was noted; she remained severely lethargic over the next few days and was subsequently transferred to the Neurological Institute. Past medical history was significant in that the patient had suffered from a left torticollis since early childhood, which had been successfully treated by tenotomy of the sternal head of the left sternocleidomastoid muscle six years before this event. When seen on admission, the patient was quite drowsy with severe neck stiffness and positive meningeal signs. No bruits were heard. Mild left hemiparesis was present. Lumbar puncture revealed grossly bloody spinal fluid under a pressure of $200 \mathrm{~mm} \mathrm{H}_{2} \mathrm{O}$. Bilateral carotid angiograms revealed an arteriovenous malformation in the right posterior thalamic region fed mostly by the posterior choroidal branches of the posterior cerebral artery. A pneumoencephalogram demonstrated mild ventricular dilatation and an incisural block. The patient improved progressively and returned to work four months later.

In October 1966 a sclerosing haemiangioma of the sternum was removed. When last seen in April 1968 she was free of symptoms.

\section{CASE 3}

This 60 year old right-handed man was admitted to the New York Neurological Institute for the first time in 1963, with a history of spasmodic retrocollis since the age of 19 years. Because of the increased frequency and severity of his movement disorder he was admitted to a hospital in Florida where bilateral carotid angiograms revealed a large AVM in the right parietal region fed by branches of the right middle cerebral artery. He was transferred to the New York Neurological Institute for further management. On admission he was noted to have episodes of spasmodic involuntary hyperextension of the head, which was also slightly tilted to the right. The examination was otherwise normal. During his hospitalization he underwent section of the right anterior C1, C2, and C3 spinal nerve roots, with slight improvement of the dystonia. In May 1972 he had a brief episode of loss of consciousness, but his condition has remained stable.

\section{CASE 4}

This 10 year old, right-handed white boy was admitted to the Babies Hospital, ColumbiaPresbyterian Medical Center in January 1972 with a history of bifrontal, pulsating headaches and in- 


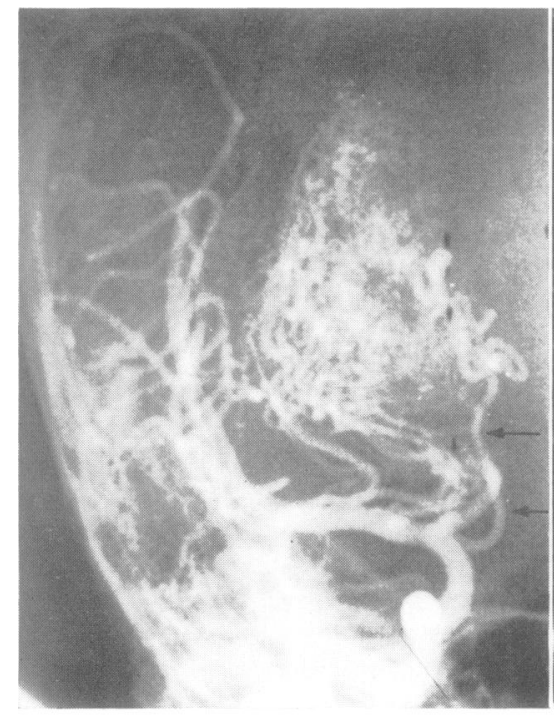

(a)

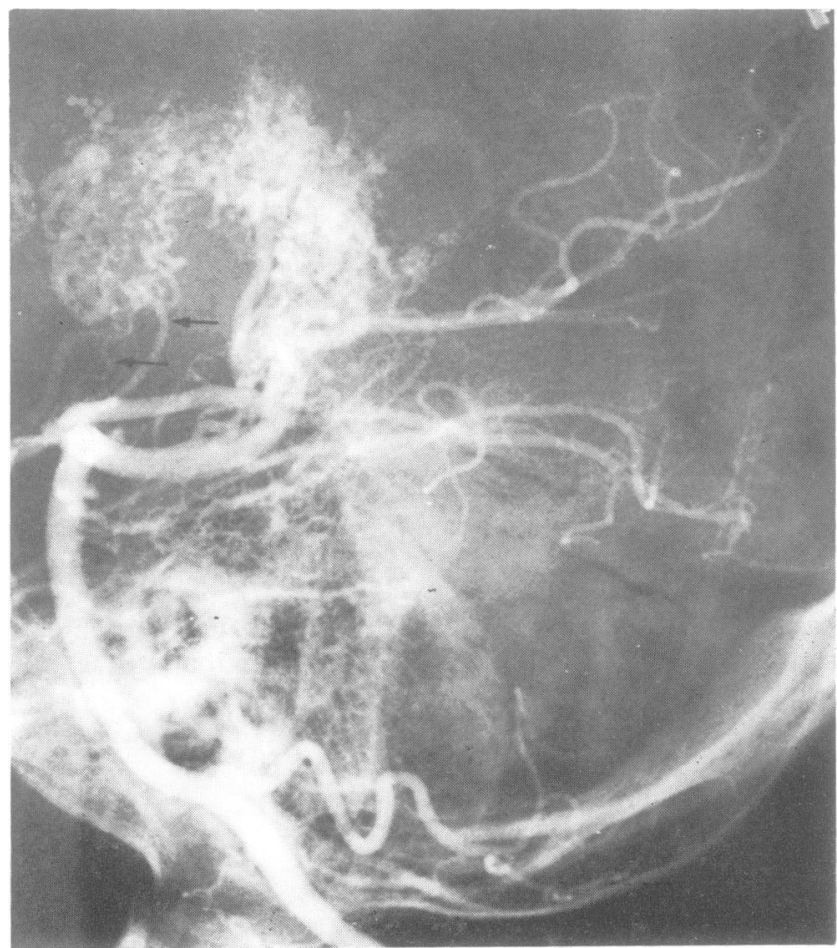

(c)

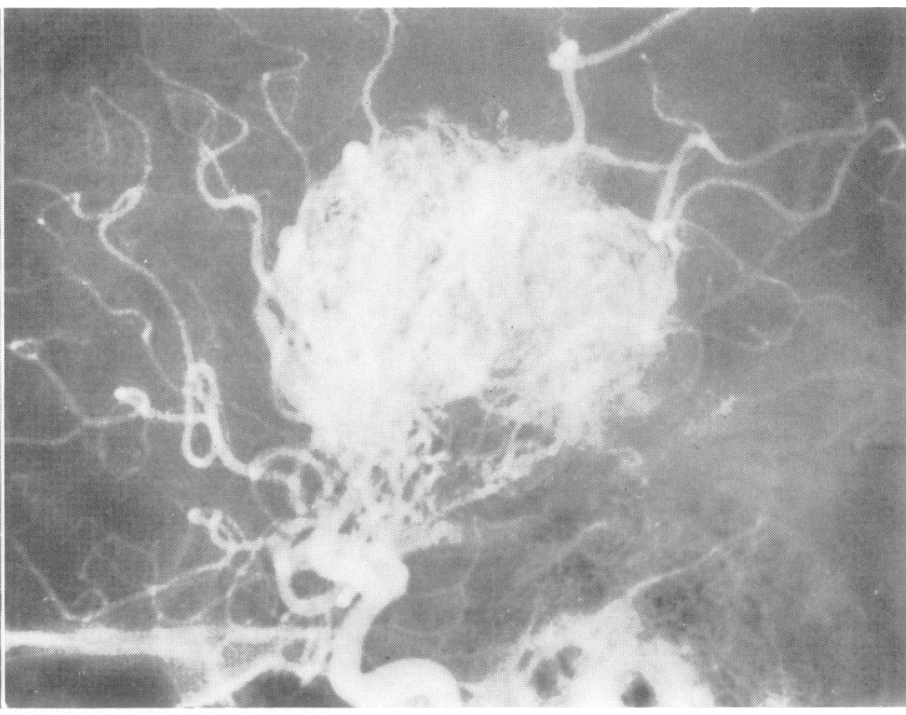

(b)

FIG. 2. Case 4. (a) AP view of the right carotid angiogram. The lateral segment of the AVM is supplied by the lenticulostriate vessels, and the medial segment by the anterior choroidal artery (arrows). Note the triangular shape of the malformation in this projection. (b) Lateral view of the same study. (c) Left vertebral angiogram showing the supply to the AVM from the posterior choroidal arteries and the thalamoperforate arteries (arrows). Note the avascular area between these two groups of vessels. 
voluntary movements of the left upper extremity, consisting of a gross tremor of the proximal segment and fine movements of the fingers. He was the product of an uncomplicated pregnancy and normal delivery. The acquisition of developmental milestones was normal. Six months before the admission the parents noted an intermittent tremor of the left arm, which increased with tension and action. This became progressively worse and he started to complain of headaches, sensation of pressure over the right retro-orbital region, blurred vision, and diplopia on conjugate gaze to the left. Because of this, he was admitted to another hospital where bilateral carotid angiograms showed an arteriovenous malformation. He was subsequently transferred to our institution for further management.

On admission he was alert and cooperative, in no distress. The head circumference was $56.5 \mathrm{~cm}$, blood pressure $116 / 80 \mathrm{mmHg}$ and pulse rate $92 / \mathrm{min}$ and regular. A prominent bruit was heard over both frontoparietal areas, synchronous with the systolic impulse. He tended to tilt the head to the left. Left central facial paresis and hemiparesis were noted, with increased tendon reflexes and an extensor plantar response on that side. There was a prominent tremor of the left upper extremity, of about 3-4 Hz present at rest and increased with voluntary motion, the hand being postured in a pseudo-athetoid way.
Rapid alternating and succession movements on the left side were performed with difficulty.

An electroencephalogram was normal. Right carotid and left vertebral angiograms were obtained by a femoral approach (Fig. 2a, b, c). These showed a large AVM occupying the right basal ganglia, thalamus, and upper mesencephalon. This malformation was supplied by hypertrophied lenticulostriate arteries, anterior choroidal artery, and perforating branches of the posterior communicating and posterior cerebral arteries. The superior and dorsal segments were nourished by large posterior choroidal vessels. An area of avascularity was noted in the ventral segment of the upper mesencephalon. The venous drainage depended upon enlarged thalamostriate and internal cerebral veins.

The patient was discharged but was readmitted two months later because of increasing headaches, anorexia, and vomiting. The neurological examination was unchanged except for evidence of early papilloedema. Lumbar puncture revealed clear fluid under a pressure of $320 \mathrm{~mm} \mathrm{H}_{2} \mathrm{O}$, with normal cells, sugar, and protein. Six days later bifrontal trephinations were done and a pneumoventriculogram performed which revealed dilatation of both lateral ventricles, with obstruction of both foramina of Monro. This was thought to be due to dilatation of the thalamostriate veins. A biventricular-atrial shunt

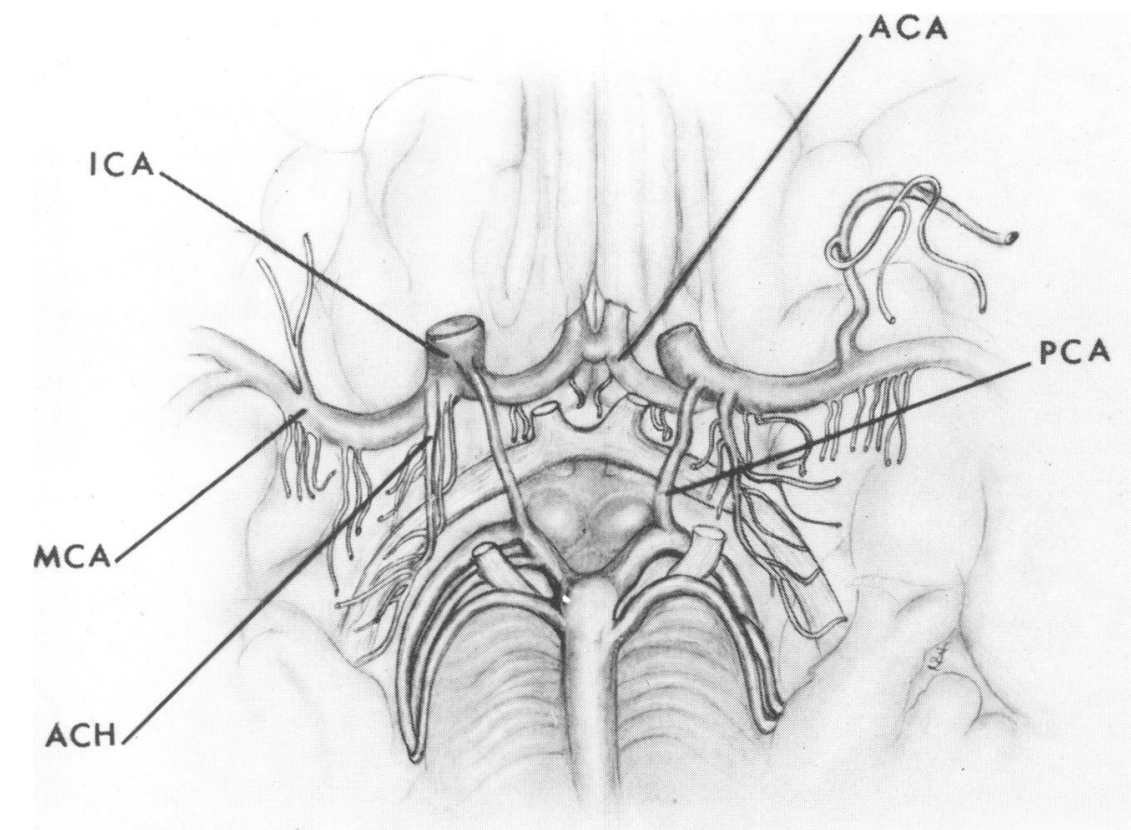

FIG. 3. Perforating arteries at the base of the brain. ICA: internal carotid artery; ACA: anterior cerebral artery; PCA: posterior communicating artery; $\mathrm{ACH}$ : anterior choroidal artery (modified from Alexander, 1941). 
using a medium pressure Hakim valve was then inserted with good improvement of the headache. Two weeks later selective embolization of the malformation in the left vertebral artery was attempted. Thirty-one silastic balls of 1 and $1.5 \mathrm{~mm}$ in diameter were instilled with slight reduction of the vascularity of the lesion.

In April, he was admitted again because of low back pain. The neurological examination was unchanged. Lumbar puncture revealed a pressure of $0 \mathrm{~mm} \mathrm{H}_{2} \mathrm{O}$. The following month he reentered the hospital for another embolization. The procedure was terminated after one ball entered the right posterior inferior cerebellar artery. His condition has remained unchanged.

\section{DISCUSSION}

Few areas of the brain receive as rich and overlapping a blood supply as the basal ganglia

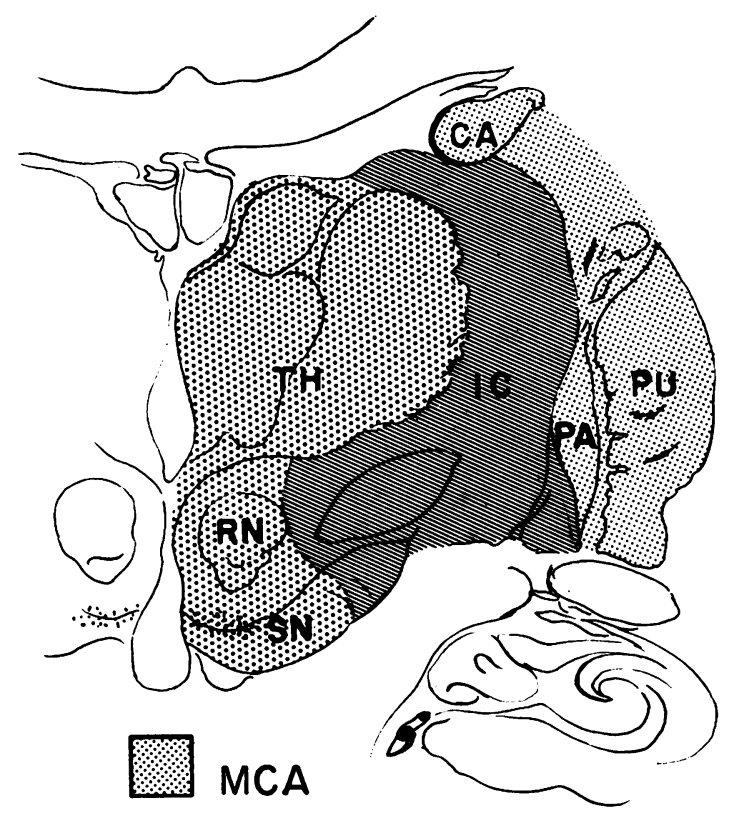

\section{$\mathrm{ACH}$}

\section{PCA}

FIG. 4. Vascular supply of the thalamus and basal ganglia. CA: caudate nucleus; PU: putamen; PA: pallidum; IC: internal capsule; $\mathrm{TH}$ : thalamus; $\mathrm{RN}$ : red nucleus; $\mathrm{SN}$ : substantia nigra; MCA: middle cerebral artery; $\mathrm{ACH}$ : anterior choroidal artery; PCA: posterior communicating artery (modified from Mettler et al., 1954). region (Foix and Hillemand, 1925; Abbie, 1933; Alexander, 1942; Mettler et al., 1956; Kaplan, 1958; Truex and Carpenter, 1969; Salamon, 1971). The central or ganglionic branches originating from the proximal segments of all the major intracranial arteries feed this region (Figs 3 and 4). The striatum is nourished by the perforating branches of the anterior and middle cerebral artery, except for the most caudal part of the putamen and the tail of the caudate nucleus which are fed by the anterior choroidal artery. This vessel also supplies the globus pallidus, except for its lateral portions which are fed by the lenticulostriate branches of the middle cerebral artery. On occasion, part of the medial segment may receive branches from the posterior communicating artery. The vascularization of the thalamus has been reviewed recently (Lazorthes and Salamon, 1971). It receives its major supply from branches of the posterior communicating and posterior cerebral arteries through perforating branches (thalamoperforating arteries) and the posterior choroidal vessels. Branches of the anterior choroidal artery nourish the ventrolateral segment of the thalamus. The vascular supply of the subthalamic nucleus, red nucleus, and substantia nigra depends on branches of the posterior communicating and posterior cerebral arteries. The venous drainage? of the basal ganglia is through the deep cerebral veins, by way of the internal cerebral vein and the great cerebral vein of Galen. These are the vessels primarily involved in AVMs of the basal ganglia and thalamus as one would expect from the embryological development of the vascular system of the brain (Kaplan et al., 1961).

Despite this plethora of vascular channels, arteriovenous malformations are infrequently found in the region of the basal ganglia and thalamus. In our survey only $7 \cdot 6 \%$ of supratentorial AVMs were found to involve these structures. The same appears to be true for neoplastic lesions (McKissock and Paine, 1958; Tovi et al., 1961; Cheek and Taveras, 1966). It is therefore not surprising that extrapyramidal syndromes are only rarely seen with such lesions. Equally rare in such instances is the so-called 'thalamic syndrome' originally described by Dejerine and Roussy (1906), in which choreoathetoid movements involving the paretic limbs may occur. In two cases an AVM causing this 
TABLE

CLINICAL AND ANGIOGRAPHIC CHARACTERISTICS

\begin{tabular}{|c|c|c|c|c|c|c|c|c|}
\hline Cases & Sex & $\begin{array}{c}\text { Age of } \\
\text { onset } \\
(y r)\end{array}$ & $\begin{array}{c}\text { First } \\
\text { symptoms }\end{array}$ & $\begin{array}{c}\text { Sub- } \\
\text { arachnoid } \\
\text { haemorrhage } \\
(S A H)\end{array}$ & $\begin{array}{c}\text { Type and site of } \\
\text { involuntary movements } \\
(A I M) \dagger\end{array}$ & Site of $A V M$ & Feeding vessels & Follow-up \\
\hline $\begin{array}{l}\text { Paterson } \\
\text { et al. (1956) }\end{array}$ & NR & NR* & NR & NR & $\begin{array}{l}\text { Athetoid movements } \\
\text { of the hemiparetic } \\
\text { limbs (site?) }\end{array}$ & 'Central' & NR & NR \\
\hline $\begin{array}{l}\text { Shaw et al. } \\
\text { (1927) }\end{array}$ & $\mathbf{M}$ & 19 & $\begin{array}{l}\text { Subarachnoid } \\
\text { bleeding }\end{array}$ & + & L. torticollis & NR & $\begin{array}{l}\text { R. middle } \\
\text { cerebral artery }\end{array}$ & $\begin{array}{l}\text { AIM subsided } \\
\text { completely } \\
\text { two years later }\end{array}$ \\
\hline \multicolumn{9}{|l|}{ Our cases } \\
\hline Case 1 & $\mathbf{M}$ & $\left(\mathrm{CH}_{1}\right.$ & $\begin{array}{l}\text { 'Waving' } \\
\text { movements } \\
\text { of R. arm }\end{array}$ & $\stackrel{+}{+}$ & $\begin{array}{l}\text { AIM unclassifiable } \\
\downarrow \\
\text { Tremor } \\
\downarrow \\
\text { Dystonia (R. upper } \\
\quad \text { extremity) }\end{array}$ & $\begin{array}{l}\text { L. thalamus, } \\
\text { basal ganglia } \\
\text { and upper } \\
\text { mesencephalon }\end{array}$ & $\begin{array}{l}\text { L. anterior } \\
\text { choroidal and } \\
\text { perforating } \\
\text { branches of } \\
\text { post. comm. } \\
\text { and post. } \\
\text { cereb. }\end{array}$ & $\begin{array}{l}\text { AIM subsided } \\
\text { after first } \\
\text { SAH }\end{array}$ \\
\hline Case 2 & $\mathbf{F}$ & 'Child- & L. torticollis & + & L. torticollis & $\begin{array}{c}\text { R. posterior } \\
\text { thalamus }\end{array}$ & $\begin{array}{l}\text { R. lateral post. } \\
\text { choroidal }\end{array}$ & $\begin{array}{l}\text { Improvement } \\
\text { after tenotomy } \\
\text { L. sterno- } \\
\text { cleidomastoid }\end{array}$ \\
\hline Case 3 & $\mathbf{M}$ & 19 & Retrocollis & 0 & Retrocollis & R. parietal lobe & $\begin{array}{r}\text { R. middle } \\
\text { cerebral }\end{array}$ & $\begin{array}{l}\text { Minimal im- } \\
\text { provement } \\
\text { after section of } \\
\text { R. } C_{1}, C_{2}, C_{3} \text {, } \\
\text { ant. roots }\end{array}$ \\
\hline Case 4 & $\mathbf{M}$ & 9 & $\begin{array}{l}\text { Tremor of } \mathbf{L} . \\
\text { arm }\end{array}$ & 0 & $\begin{array}{l}\text { Tremor and dystonic } \\
\text { posture of } \mathrm{L} \text {. upper } \\
\text { extremity }\end{array}$ & $\begin{array}{l}\text { R. thalamus, } \\
\text { basal ganglia } \\
\text { and upper } \\
\text { mesencephalon }\end{array}$ & $\begin{array}{l}\text { R. lenticulo- } \\
\text { striate, ant. } \\
\text { choroidal, and } \\
\text { perforating } \\
\text { branches of } \\
\text { post. comm. } \\
\text { and post. } \\
\text { cereb. }\end{array}$ & $\begin{array}{l}\text { No improvement } \\
\text { after partial } \\
\text { selective } \\
\text { embolization } \\
\text { of AVM }\end{array}$ \\
\hline
\end{tabular}

* NR: not recorded.

† AIM : abnormal involuntary movements.

type of picture, but without abnormal movements, have been documented (Silver, 1957; Waltz and Ehni, 1966).

The clinical and angiographic characteristics of two previously reported patients and the four cases in this series are summarized in the Table. An intimate correlation exists between the laterality of the symptoms and the site of the AVM. However the symptomatology is variable and may result from differing mechanisms.

Arteriovenous malformations may become symptomatic in several different ways (Pool, 1972). The large volume of blood which is shunted through the AVM may result in a 'steal effect' from normal tissues with temporary or permanent ischaemia of neuronal structures. In our case 3, and in the case reported by Shaw et al. (1972) this type of phenomenon can be implicated. The size of the AVM may be such as to produce a mass effect with impingement on basal ganglia structures. This may well have been operative in case 1 where a shift of the midline structures to the opposite side was consistently found long before a known or significant bleeding episode occurred. Major or minor haemorrhages may occur within and contiguous to the abnormal vessels and lead to the formation of haematomas with pressure upon and necrosis of adjacent neural tissue. It is also conceivable that, in association with maldeveloped blood vessels, abnormalities in brain development may occur. Because of these various factors, the clinical picture may be variable and labile. Initial symptoms may subside, increase in severity, or be replaced by new ones as any one of the above mechanisms become operative.

Case 1 in our series is particularly illustrative of many of these aspects. In this patient 'waving' movements of one hand, undoubtedly dyskinetic in nature, were noted at 1 year of age. At the age 
of 12 years they were replaced by tremor at rest, and, after an episode of bleeding at the age of 25 , he began to have flailing dystonic movements; the latter subsided completely within one week. Hence, an interesting spectrum of abnormal movements occurred whose pathological substrate is difficult to establish. However, from the site at which the AVM was located, which included the mesencephalon, one might suspect the pathways involved. Experimentally, tremor at rest simulating tremor of Parkinsonism has been produced in the monkey by lesions placed in the ventromedial tegmental area of the mesencephalon at the level of the substantia nigra and red nuclei (Poirier et al., 1966). Such lesions destroy the pars compacta of the substantia nigra and interrupt pathways to the striatum, pallidum, and thalamus as well as rubrospinal and tegmentospinal tracts. It is postulated that tremor results from interruption of the dopaminergic nigrostriatal pathway which is thought to exert an inhibitory effect on the pallidum (Poirier et al., 1965). Other types of dyskinetic movements may similarly represent disturbances of internal circuitry in the basal ganglia resulting in loss of inhibitory phenomena. Experimentally, choreoid and ballistic movements may be produced in monkeys by lesions localized to the contralateral subthalamic nucleus, which probably has an inhibitory influence upon the globus pallidus (Carpenter et al., 1950). The disappearance of the abnormal movements in this case was probably due to involvement of the corticospinal tract at the posterior limb of the internal capsule with development of mild hemiparesis. However, destruction of the pallidum, ventrolateral nuclei of the thalamus, or the pallidothalamic connection fibres could well have occurred and abolished the dyskinetic movements. As is well known, lesions placed in these structures in man have effectively alleviated abnormal movements. Angiographically, the malformation was fed in its lateral portion by the anterior choroidal artery, and in its posterior and most medial aspect by large thalamoperforating vessels. These involved primarily the pallidum, thalamus, upper mesencephalon, and probably part of the internal capsule. It should be emphasized that both anterior and posterior segments of the internal capsule are supplied by perforating branches of the middle cerebral artery, except for the ventral segment of the posterior limb and the retrolenticular portion which depend upon the anterior choroidal artery. This was one of the major feeding vessels. The progressive nature of this lesion is evident in the two angiograms performed seven years apart, which reveal an increase in the bulk of the lucent area in the medial segment of the malformation. The presence of bilateral sternocleidomastoid hypertrophy is certainly intriguing. This usually occurs in cases of dystonia, due to the rhythmic, powerful contractions of the muscles involved, but no dystonic or torsion movements were apparent in our case.

The association of spasmodic torticollis and AVM in our cases 2 and 3 , and in the case reported by Shaw et al. (1972), deserves comment. In case 2 , the malformation was localized to the dorsal thalamus and was fed by the posterior choroidal arteries. In case 3, as well as in the case of Shaw et al., the AVM was nourished by branches of the middle cerebral artery, and one wonders whether or not the association is merely coincidental. The contralaterality of the signs and the succession of events in the latter patient suggest some intimate relationship. The dystonia followed an episode of subarachnoid bleeding persisting for two years and then subsiding. Possibly this resulted from relative vascular insufficiency-so-called steal phenomenonbut unfortunately a study of the posterior fossa circulation was not carried out. It is of interest to note that the anatomical substrate of this disorder remains to be established (Tarlov, 1970). Spasmodic torticollis has been seen in patients who have suffered an attack of encephalitis lethargica. It has been reported in a patient with colloid cyst of the third ventricle and improved after it was removed (Avman and Arasil, 1969). Experimentally, spasmodic torticollis has been produced in the monkey by lesions involving the medial mesencephalic reticular formation, caudal and dorsal to the red nucleus at the level of the descussation of the brachium conjunctivum (Foltz et al., 1959); tonic neck torsion follows lesions in the red nucleus (Carpenter, 1956) or between the red nucleus and the interstitial nucleus of Cajal (Denny-Brown, 1962). Its anatomical substrate is, however, far from established.

The angiographic features of the AVM in our 
case 4 , are worthy of comment. In this case the rostral portion of the malformation shows two distinct segments - the lateral one fed by hypertrophied lenticulostriate arteries and the medial one supplied by a large anterior choroidal vessel. In the anteroposterior view, the AVM is triangular in shape conforming to the outline of the basal ganglia in this projection, and the angiographic film is quite similar to an injected specimen. The caudal part of the AVM receives large perforating branches of the posterior communicating and posterior cerebral arteries. An area of avascularity corresponding to the ventral part of the upper mesencephalon is well visualized within the AVM. Ischaemia of that area which includes the substantia nigra and its efferent fibres, either because of occlusion of the vessels or by a steal effect, may have been the cause of the extrapyramidal phenomena in this patient. Although not entirely pertinent to our subject we would like to call attention to the presence of hydrocephalus in this case. This was felt to be due to obstruction of both foramina of Monro by enlarged thalamostriate veins. As far as we could determine this mechanism has not been reported.

The treatment of these malformations presents a formidable problem for which no fully satisfactory therapeutic measures are available. A direct surgical attack on the AVM is rarely feasible except in the exceptional case in which the dimensions of the lesion are small and their proximity to the lateral ventricle allows a transventricular approach (Carton and Hickey, 1955; Ralston and Papatheodorou, 1960). Attempts to reduce the size of the abnormal collection of vessels by promoting thrombosis have been less than satisfactory. Initially, this was attempted by irradiation, more recently by embolization (Luessenhop et al., 1965). The latter may be more successful using selective catheterization of the feeding vessels (Hilal and Michelsen, 1972). However, at present it may be more judicious to avoid any intervention and restrict treatment to symptoms as they occur.

We are grateful to Dr. James W. Correll and Dr. Jost Michelsen for permission to report their cases.

\section{REFERENCES}

Abbie, A. A. (1933). The clinical significance of the anterior choroidal arteries. Brain, 56, 233-246.
Alexander, L. (1942). The vascular supply of the striopallidum. Research Publication Association for Research Nervous and Mental Disease, 21, 77-132.

Anderson, F. M., and Korbin, M. A. (1958). Arteriovenous anomalies of the brain. A review and presentation of 37 cases. Neurology (Minneap.), 8, 89-101.

Avman, N., and Arasil, E. (1969). Spasmodic torticollis due to colloid cyst of the third ventricle. Acta Neurochirurgica, 21, 265-268.

Carpenter, M. B. (1956). A study of the red nucleus in the rhesus monkey. Anatomical degenerations and physiologic effects resulting from localized lesions of the red nucleus. Journal of Comparative Neurology, 105, 195-249.

Carpenter, M. B., Whittier, J. R., and Mettler, F. A. (1950). Analysis of choreoid hyperkinesia in the rhesus monkey. Journal of Comparative Neurology, 92, 293-332.

Carlton, C. A., and Hickey, W. C. (1955). Arteriovenous malformation of the head of the caudate nucleus. Report of a case with total removal. Journal of Neurosurgery, 12, 414418.

Cheek, W. R., and Taveras, J. M. (1966). Thalamic tumors. Journal of Neurosurgery, 24, 505-513.

Dejerine, J., and Roussy, G. (1906). Le syndrome thalamique. Revue Neurologique, 14, 521-532.

Denny-Brown, D. (1962). The midbrain and motor integration. Proceedings of the Royal Society of Medicine, 55, 527 538.

Foix, C., and Hillemand, P. (1925). Les artères de l'axe encéphalique jusqu'au diencéphale inclusivement. Revue Neurologique, 32, 705-739.

Foltz, E. L., Knopp, L. M., and Ward, A. A., Jr. (1959). Experimental spasmodic torticollis. Journal of Neurosurgery, 16, 55-72.

Hilal, S. K., and Michelsen, J. (1972). Personal communication.

Kaplan, H. A. (1958). Vascular supply of the base of the brain. In Pathogenesis and Treatment of Parkinsonism, pp. 138-160. Edited by W. S. Fields. Thomas: Springfield.

Kaplan, H. A., Aronson, S. M., and Browder, E. J. (1961). Vascular malformations of the brain. An anatomical study. Journal of Neurosurgery, 18, 630-635.

Kelly, D. L., Jr., Alexander, E., Jr., Davis, C. H., Jr., and Maynard, D. C. (1969). Intracranial arteriovenous malformations; clinical review and evaluation of brain scans. Journal of Neurosurgery, 31, 422-428.

Lazorthes, G., and Salamon, G. (1971). The arteries of the thalamus: an anatomical and radiological study. Journal of Neurosurgery, 34, 23-26.

Luessenhop, A. J., Kachmann, R., Jr., Shevlin, W., and Ferrero, A. A. (1965). Clinical evaluation of artificial embolization in the management of large cerebral arteriovenous malformations. Journal of Neurosurgery, 23, 400417.

Mackenzie, I. (1953). The clinical presentation of the cerebral angioma. A review of 50 cases. Brain, 76, 184-214.

McKissock, W., and Paine, K. W. E. (1958). Primary tumours of the thalamus. Brain, 81, 41-63.

Mettler, F. A., Cooper, I., Liss, H. R., Carpenter, M., and Noback, C. (1954). Patterns of vascular failure in the central nervous system. Journal of Neuropathology and Experimental Neurology, 13, 528-539.

Mettler, F. A., Liss, H. R., and Stevens, G. H. (1956). Blood supply of the primate striopallidum. Journal of Neuropathology and Experimental Neurology, 15, 377-383.

Moody, R. A., and Poppen, J. L. (1970). Arteriovenous malformations. Journal of Neurosurgery, 32, 503-511.

Olivecrona, H., and Riives, J. (1948). Arteriovenous aneurysms of the brain. Their diagnosis and treatment. Archives of Neurology and Psychiatry, 59, 567-602. 
Paterson, J. H., and McKissock, W. (1956). A clinical survey of intracranial angiomas with special reference to their mode of progression and surgical treatment: a report of 110 cases. Brain, 79, 233-266.

Perret, G., and Nishioka, H. (1966). Report on the cooperative study of intracranial aneurysms and subarachnoid hemorrhage. Section VI. Arteriovenous malformations. Journal of Neurosurgery, 25, 467-490.

Poirier, L. J., and Sourkes, T. L. (1965). Influence of the substantia nigra on the catecholamine content of the striatum. Brain, 88, 181-192.

Poirier, L. J., Sourkes, T. L., Bouvier, G., Boucher, R., and Carabin, S. (1966). Striatal amines, experimental tremor and the effect of harmaline in the monkey. Brain, 89, 37-52.

Pool, J. L. (1972). Arteriovenous malformations of the brain. In Handbook of Clinical Neurology, pp. 227-266. Vol. 12. Edited by P. J. Vinken and G. W. Bruyn. North-Holland: Amsterdam.

Ralston, B. L., and Papatheodorou, C. A. (1960). Vascular malformation of the left thalamus. Journal of Neurosurgery, 17, 505-510.

Salamon, G. (1971). Atlas de la Vascularisation Artérielle du Cerveau chez l'Homme. Sandoz: Paris.
Shaw, K. M., Hunter, K. R., and Stern, G. M. (1972). Medical treatment of spasmodic torticollis. Lancet, 1, 1399.

Silver, M. L. (1957). 'Central pain' from cerebral arteriovenous aneurysm. Journal of Neurosurgery, 14, 92-96.

Svien, H. J., and McRae, J. A. (1965). Arteriovenous anomalies of the brain. Fate of patients not having definite surgery. Journal of Neurosurgery, 23, 23-28.

Tarlov, E. (1970). On the problem of the pathology of spasmodic torticollis in man. Journal of Neurology, Neurosurgery, and Psychiatry, 33, 457-463.

Tönnis, W., Schiefer, W., and Walter, W. (1958). Signs and symptoms of supratentorial arteriovenous aneurysms. Journal of Neurosurgery, 15, 471-480.

Tovi, D., Schisano, G., and Liljeqvist, B. (1961). Primary tumors of the region of the thalamus. Journal of Neurosurgery, 18, 730-740.

Truex, R. C., and Carpenter, M. B. (1969). Human Neuroanatomy, 6th edn. Williams and Wilkins: Baltimore.

Waltz, T. A., and Ehni, G. (1966). The thalamic syndrome and its mechanism. Report of two cases, one due to arteriovenous malformation in the thalamus. Journal of Neurosurgery, 24, 735-742. 